\title{
ФОРМИРОВАНИЕ ДЕЦЕНТРАЛИЗОВАННЫХ ФИНАНСОВЫХ ИНСТИТУТОВ В КАЧЕСТВЕ АЛЬТЕРНАТИВЫ КРЕДИТНО-ФИНАНСОВЫМ ОРГАНИЗАЦИЯМ
}

\author{
(c) 2021 Фомин Дмитрий Александрович \\ аспирант департамента «Экономическая теория» \\ Финансовый университет при Правительстве Российской Федерации, Россия, Москва \\ E-mail: fomin.lopukhin@gmail.com
}

Кризис 2020 года привлек на рынок цифровых активов новых инвесторов. Это дало импульс развитию сферы децентрализованных финансов - нового направления в индустрии криптовалют, которое способно конкурировать с традиционными финансовыми институтами, в числе которых банки, эскроу-агенты и другие кредитно-финансовые организации. В статье рассматриваются функции институтов нового типа и факторы, способствующие притоку капитала в данную индустрию.

Ключевые слова: блокчейн, децентрализация, смарт-контракт, криптовалюта, криптобиржа, токен, банк, финансы.

Вызванный пандемией коронавируса кризис ударил по мировой экономике. Одним из инструментов решения возникших экономических проблем было выбрано снижение центральными банками ключевых ставок. Это негативно сказалось на доходности банковских депозитов. Ситуация усугубилась из-за падения котировок мировых валют, вызванного увеличением денежной массы. В частности, пострадал доллар, который считается защитным активом. Индекс DXY, показывающий стоимость доллара по отношению к корзине из шести мировых валют с мая 2020 года по февраль 2021 года снизился со 100 до 90,3 пункта.

Снижение доходности банковских депозитов, а также ослабление резервных валют спровоцировало рост среди инвесторов интереса к альтернативным способам сбережения капитала. В первую очередь средства были направлены на фондовый рынок. Но не меньше инвесторов привлек рынок криптовалют, при этом не только розничных пользователей. В цифровые активы, преимущественно в биткоин, стали инвестировать игроки институционального уровня. В их числе оказалась компания Илона Маска Tesla, которая вложила в первую криптовалюту \$1,5 млрд. Также биткоин приобрели производитель аналитического программного обеспечения Microstrategy - на \$1 млрд., американская страховая компания MassMutual и другие. Кроме них работой с криптовалютой заинтересовалась крупнейшая в мире инвестиционная компания BlackRock, под управлением фондов которой находятся активы на $\$ 8,7$ трлн.

На фоне повышенного интереса к криптовалюте импульс получил новый сектор крипторынка - децентрализованные финансы.* Этот сектор предлагает решения, которые по своим функциям заменяют традиционные финансовые институты и работают с большей эффективностью, считает профессор Базельского университета Фабиан Шер [2]. Сформировавшиеся институты, преимущественно кредитно-финансовые учреждения, централизованы и существуют на доверии клиентов. Децентрализованные сервисы, напротив, не нуждаются в этом доверии благодаря использованию смарт-контрактов и распределённого реестра. За счет данной технологии децентрализованные сервисы могут брать на себя роль третьей стороны - банка или иного финансового агента, выполняющего функции депозитария финансовых активов, эскроуагента и других институтов.

Схожей позиции придерживаются ученые Дирк А.Зетше, Дуглас В.Арнер и Росс П.Бакли [3]. В работе, посвященной децентрализованным финансам, они предположили, что данное направление в будущем может быть ассимилировано традиционным финансовым сектором. В частности, децентрализованные сервисы будут пользоваться высоким спросом в развивающихся странах с низким уровнем развития финан-

\footnotetext{
* Decentralized Finance (далее DeFi) - децентрализованные сервисы, которые работают на блокчейне и предлагают финансовые услуги. Разработчики таких платформ не имеют доступа к хранимым на них средствам, а дальнейшее развитие проекта определяется сообществом.
} 
совых институтов и слабой или отсутствующей системой регулирования. В таких государствах компаниям, чтобы получить доступ к финансовым услугам, приходится использовать дорогостоящие решения в других юрисдикциях. Запуск бизнес-центров по этой и другим причинам проблематичен и нерационален, чего нельзя сказать о DeFi-решениях.

Есть несколько предпосылок к тому, что традиционный финансовый сектор будет ассимилировать децентрализованные технологии. В первую очередь, для кредитно-финансовых институтов это возможность сократить трансакционные и операционные издержки и автоматизировать определённые процессы. Также внедрение блокчейна позволит организациям повысить свою рентабельность, заняв на рынке криптовалют нишу, которую могут оккупировать набирающие популярность криптобиржи [1].

Чтобы понять, чем обусловлена привлекательность децентрализованных финансов и насколько они способны перерасти в самостоятельную институциональную среду, рассмотрим, что предлагает эта сфера и какие ее преимущества. В основном DeFi-сервисы разделяются на два направления решений. Первое - протоколы, с помощью которых можно торговать цифровыми активами, такими как Ethereum и токенами на его основе. Второе направление - платформы для лендинга и кредитования. Ha DeFi-cepвисах пользователи могут открыть аналог вклада. Для этого инвестор временно блокирует свои цифровые активы в протоколе, таким образом предоставляя платформе свой капитал в качестве ликвидности.

Данный капитал может использоваться платформой для выдачи кредитов в криптовалюте другим пользователям, за что те свою очередь платят комиссию. Эта комиссия поступает в “пул” - общий фонд, из которого выплачиваются проценты по вкладам. Так устроены лендингплатформы.

Вклады через предоставление ликвидности инвесторы также могут открывать на децентрализованных торговых платформах. Их пользователи платят комиссии за совершение сделок по обмену цифровыми активами. За счет комиссий формируется фонд, из которого выплачиваются проценты инвесторам, предоставившим ликвидность.

Таким образом оба направления решений в сфере DeFi представляют собой аналоги традиционных финансовых институтов. Платформы для лендинга и кредитования замещают функции кредитно-финансовых учреждений. DeFi-биржи являются аналогом брокера. Однако у децентрализованных платформ есть ряд существенных преимуществ перед традиционным финансовым сектором, которые способны вызвать переток капитала из одной сферы в другую.

Первой сильной чертой является безопасность. Направление DeFi зародилось в 2016-2017 годах. Но на тот момент децентрализованные приложения не пользовались большой популярностью. Интерес к новой сфере начал расти в 2020 году, что стало следствием череды взломов, которым подверглись криптобиржи. Из-за того что угрозе быть взломанной подвержена любая, даже самая надежная торговая площадка, пользователи стали хранить криптовалюту на внебиржевых кошельках. Это специальные локальные кошельки - расширения в браузере или программы на смартфон и персональный компьютер - которые позволяют хранить цифровые активы и исключают возможность доступа к ним внешних пользователей.

Когда пользователь хранит средства в банке, держит капитал у брокера или на бирже, он доверяет свои активы на хранение сторонней компании. Так, пользователь берет на себя риск того, что компания обанкротится, пострадает из-за хакерской атаки или же по какой-либо причине заблокирует доступ к деньгам.

С внебиржевыми кошельками такие риски минимизированы. Держать на них средства безопаснее чем на централизованных сервисах. Также пользователь сохраняет полный контроль над своими активами и в то же время может пользоваться финансовыми услугами, в том числе торговать цифровыми активами через децентрализованных биржи, использовать лендингплатформы и множество других DeFi-сервисов. Для этого следует подключить к платформе цифровой кошелек и дать ей разрешение взаимодействовать с ним.

Другим и, вероятно, главным преимуществом DeFi-рынка перед традиционными финансами являются высокие процентные ставки за предоставление ликвидности. Этот аспект стал особенно актуальным в кризис, во время которого значительно упали ключевые ставки по всему миру. В России максимальные процентные ставки по вкладам физических лиц в 
рублях составляют 4,8-4,9\%, согласно данным Банка России по состоянию на февраль 2021 года. Доходность по депозитам в долларах США колеблется в диапазоне от 0,38 до 1,3\%. Такая доходность с трудом покрывает инфляцию.*

Доходность по депозитам в секторе децентрализованных финансов значительно выше. Ставки за предоставление ликвидности DeFi-сервисам, как правило, составляют 5-7$10 \%$ годовых и более. Без труда можно найти и более выгодные предложения, когда доходность депозитов в DeFi составляет десятки процентов, однако и риски в этих случаях выше.

Следует отметить, что ставки по вкладам в децентрализованных приложениях плавающие. Их величина зависит от нескольких факторов. В первую очередь это объем средств, внесенных всеми пользователями DeFi-платформы в качестве депозитов - чем показатель выше, тем доходность ниже. Также роль играет активность пользователей. Чем больше они совершают операций, тем больше средств в виде комиссий поступает в фонд, из которого выплачиваются ставки по депозитам.

Важное значение имеет цена актива, в котором инвесторы вносят депозит и получают выплаты. Если для этих целей пользователь выбрал криптовалюту с нефиксированным курсом, от его колебаний будет зависеть конечная доходность вклада. Такой подход создает существенные риски - можно потерять часть вложенного капитала на обесценении базового актива. Но эти риски можно нивелировать, если вносить депозиты в стейблкоинах - цифровых токенах с фиксированным курсом.

Наиболее востребованным среди стейблкоинов по состоянию на 1 февраля 2021 года является токен компании Tether (USDT). Это криптодоллар, курс которого привязан к котировкам американского доллара. Капитализация USDT превышает $\$ 30$ млрд. Это на 350\% больше, чем у ближайшего конкурента USDT - токена USDC, капитализация которого составляет \$6,5 млрд., согласно данным сервиса Coinmarketcap.***

Предоставляя ликвидность в USDT и других стейблкоинах децентрализованным сервисам, пользователи могут полностью уйти от нужды открывать вклады в банках. DeFi-приложения предлагают в разы большую доходность по депозитам, включая депозиты в токенах на иностранную валюту.

Значение также имеет над-национальный характер индустрии. Инвесторы и рядовые пользователи из стран, где слабо развита банковская система или же наблюдается устойчивая девальвация национальной валюты, проявляют повышенный интерес к рынку криптовалют. Об этом говорят данные Google Trends, согласно которым наибольшей популярностью биткоин пользуется в Нигерии и ЮАР. Доктор Марк ван Риджменам отмечает, что децентрализованные сервисы могут стать интернациональным решением для бедных слоев населения, не имеющих доступа к услугам банков [4].

Перечисленные характеристики, а также многократный рост цены выпущенных DeFi-платформами цифровых активов стали причиной для существенного притока капитала на этот рынок. По состоянию на 1 января 2020 года объем средств, заблокированных в DeFi-сервисах, составлял менее $\$ 1$ млрд. В феврале 2021 года этот показатель превысил $\$ 40$ млрд., согласно данным агрегатора Defipulse.**** Это сумма активов, которые были временно заблокированы инвесторами на разных децентрализованных платформах в рамках предоставления ликвидности и для других целей.

Темп притока капитала в сектор DeFi ускорится, если будут устранены несколько сдерживающих факторов. В первую очередь проблемой является чрезмерный размер комиссий. Абсолютное большинство децентрализованных приложений работает на блокчейн-платформе Ethereum. То есть программный код DeFi-сервисов был запущен и функционирует внутри сети данной криптовалюты. За совершение любой операции в блокчейне Ethereum требуется оплатить комиссию. Ее размер зависит от нагрузки на сеть криптовалюты. Чем нагрузка выше - тем выше комиссия.

Taк как DeFi-сервисы работают на блокчейне Ethereum, то рост количества их пользова-

\footnotetext{
* Данные Банка России о базовом уровне доходности вкладов за февраль 2021 года [электронный ресурс]. URL: https://cbr.ru/Collection/Collection/File/31923/budv-2021-02.pdf.

** Информационный ресурс для отслеживания цены и других параметров криптовалют Coinmarketcap [электронный ресурс]. URL: https://coinmarketcap.com (дата обращения: 14.02.2021).

*** Агрегатор данных о рынке децентрализованных финансов Defipulse [электронный ресурс]. URL: https://defipulse.com (дата обращения: 17.02.2021).
} 
телей привел к колоссальной нагрузке на сеть цифрового актива. На момент написания материала на децентрализованную биржу Uniswap приходится наибольший объем комиссий в сети Ethereum. Рост нагрузки соответствующим образом сказался на размере комиссий. Так, в начале 2020 года, когда сектор DeFi еще не пользовался популярностью, одна операция в сети Ethereum в среднем обходилась дешевле 10 центов, согласно данным информационного ресурca Bitinfocharts."

К концу лета, когда в этот сектор пришла первая крупная волна пользователей, средний размер комиссии за одну операцию в сети Ethereum поднимался до \$14. В феврале этот показатель достигал \$25. В данном случае речь идет о простых операциях, например, о переводе криптовалюты между цифровыми кошельками.

Однако все децентрализованные приложения задействуют не простые операции, а смартконтракты. Они представляют собой алгоритм из нескольких действий, объединённых в одну операцию. В качестве примера таких операций можно привести покупку цифровых активов через DeFi-сервисы или открытие депозита на них.

Для проведения смарт-контрактов требуется заплатить комиссии в разы большего размера. Например, единоразовый обмен цифровых активов через децентрализованные биржи в начале февраля 2021 обходился пользователям в $\$ 50-200$. Внесение ликвидности, то есть открытие депозита - это еще более сложная операция, и стоимость ее выше.

Такие жуткие комиссии сделали использование децентрализованных сервисов на базе Ethereum крайне невыгодным для розничных пользователей с небольшим капиталом. Однако Данная проблема находится в стадии устранения, разработчики Ethereum обсуждают внедрение нового протокола, а также готовятся к обновлению блокчейна криптовалюты до второй версии.

Оба решения направлены в том числе на борьбу с высокими комиссиями, снижение размера которых вновь откроет этот рынок для розничных инвесторов. Нормализация комиссий также упростит процесс разработки новых децентрализованных платформ, так как их тестирование ввиду высоких комиссий обходится слишком дорого. Альтернативным для индустрии решением может стать переход пользователей и перенос существующей инфраструктуры на другие блокчейн-платформы с более низкими комиссиями. Конкурентами Ethereum выступают системы Binance Smart Chain, Tron и другие.

Другая существенная проблема сферы децентрализованных финансов заключается в степени ее зрелости. Это молодой, развивающийся рынок, на котором недостаточно квалифицированных кадров. По этой причине многие DeFi-сервисы обладают низким уровнем защиты и представляют собой точные копии друг друга. В данном секторе разработчику, чтобы запустить свой децентрализованный проект, достаточно открыть программный код уже существующего, скопировать его и поменять дизайн. Такая практика распространена в сфере DeFi.

Недостаточная квалификация кадров порождает две проблемы. Во-первых, ограниченный набор уникальных приложений. Многие сервисы в точности повторяют друг друга, что не приносит индустрии существенной пользы, но снижает в ней долю качественных сервисов. Во-вторых, низкий уровень защиты от сбоев и хакерских атак. Почти все DeFi-сервисы, включая самые крупные в этом секторе, подвергались хакерским атакам, в результате которых пользователи теряли средства. Взломы затронули лидеров рынка - проекты Sushi, Maker, Yearn, Compound и множество других. Причина этого кроется в том, что большинство децентрализованных приложений создается небольшой командой разработчиков, зачастую анонимных. Такое обилие хакерских атак и реализованных уязвимостей приводит к росту среди пользователей недоверия к сфере DeFi, на фоне которого традиционные финансовые институты выглядит значительно надежнее.

Важным фактором также является отсутствие регулирования. На данный момент ни в одной стране нет четкого законодательного регулирования сферы децентрализованных финансов. В связи с этим пользователи DeFi- приложений остаются без юридической защиты, которая необходима в особенности из-за перенаполненности данного сектора мошенниками. Также отсутствие законов препятствует появлению стартапов и притоку инвестиций.

\footnotetext{
* Информационный ресурс для отслеживания цены и других параметров криптовалют из открытых источников Bitinfocharts [электронный ресурс]. URL: https://bitinfocharts.com/comparison/ethereum-transactionfees. html (дата обращения: 20.02.2021).
} 
По мере разрешения перечисленных проблем их сдерживающее влияние будет сходить на нет. Это и разработка новых продуктов будет способствовать развитию индустрии и привлечению в нее новых инверторов. В их числе, вероятно, будут и игроки фондового рынка, которым не интересны криптовалюты. В секторе DeFi имеются и разрабатываются аналоги биржевых продуктов, в частности цифровые токены на ценные бумаги. Лидером в этом направлении является деривативная платформа FTX, которая выпустила цифровые токены на акции Apple, Amazon, Tesla, Facebook, Netflix и другие инструменты фондового рынка. Также в сфере DeFi имеется рынок фьючерсов и опционов.

Сектор децентрализованных финансов на данном этапе развития представляет собой колыбель ряда финансовых и других институтов нового типа. В этой сфере имеются аналоги банков, бирж, страховых организаций, платформ для торговли коллекционными предметами и других сервисов. Наличие у этих аналогов преи- муществ, таких как децентрализация и высокая доходность по депозитам, в перспективе может вызвать переток капитала из традиционного финансового сектора в сферу DeFi, что ускорит процесс замещения устоявшихся институтов.

Важно контролировать этот процесс, чтобы предупредить возможное негативное влияние на российскую экономику и извлечь выгоду. С одной стороны, укрепление статуса DeFi способно вызвать отток капитала из банковского сектора - инвесторы потянуться на новый рынок за большими ставками. В текущих реалиях сектор децентрализованных финансов вряд ли может угрожать стабильности финансовой системы РФ, но постоянно нарастающий отток капитала будет оказывать негативное влияние. С другой стороны, если способствовать развитию отрасли в юрисдикции РФ, появится возможность создавать финансовые институты нового типа и через них привлекать средства в экономику из-за рубежа.

\section{Библиографический список}

1. Михайлов А.М., Королев И.А. Трансформация современной финансовой системы и роль в ней финансовых технологий // Экономические науки.-2021. - № 1.- С. 32-35.

2. Schär F., Decentralized Finance: On Blockchain- and Smart Contract-Based Financial Markets, Federal Reserve Bank of St. Louis Review. - 2021.

3. Zetzsche D.A., Arner D. W., Buckley R. P. // Journal of Financial Regulation. - 2020.- P. 172-203.

4. How Decentralised Finance Will Change the World's Economy. [Электронный ресурс]. - режим доступа: https:// vanrijmenam.nl/decentralised-finance-change-world-economy/ (дата обращения 01.14.2021). 